\title{
EDUCAÇÃO INCLUSIVA E REDES DE APOIO: Reflexões a Partir de uma Realidade Escolar
}

\author{
Tatiane Motta da Costa e Silva ${ }^{1}$ \\ Caroline Andressa Bortoluzzi Zalamena² \\ Rodrigo de Souza Balk ${ }^{3}$
}

\begin{abstract}
RESUMO
O estudo busca analisar o contexto no qual se insere uma escola pública, a fim de identificar as estratégias de articulação e atendimento as/aos alunas/os com deficiência. Trata-se de um estudo qualitativo, caracterizado quanto aos objetivos como uma pesquisa descritiva. O procedimento de coleta de dados se deu por meio da observação participante no ambiente escolar e em locais próximos à escola, e de entrevista semiestruturada com a coordenadora pedagógica da escola e com a gestora da Estratégia de Saúde da Família (ESF) adstrita. A escola possui 1.290 alunas/os, e, destes, 53 possuem alguma deficiência. A articulação entre a escola e a ESF ocorre por meio do Programa Saúde na Escola (PSE) e pelo encaminhamento das/os alunas/ os para atendimento no serviço de saúde. Quanto as/aos alunas/os com deficiência, a ESF faz o acompanhamento de alguns casos em específico, no entanto a ESF, e nem mesmo o município, possuem uma estrutura para o atendimento de todas as especificidades. Constatamos, por fim, que a escola possui uma grande demanda de alunas/os com deficiência e, apesar da oferta de atendimento especializado, a mesma carece de um apoio complementar.
\end{abstract}

Palavras-chave: Educação. Serviços de saúde. Pessoas com deficiência.

\section{INCLUSIVE EDUCATION AND SUPPORT NETWORKS: REFLECTIONS FROM A SCHOOL REALITY}

\section{ABSTRACT}

The study seeks to analyze the context in which a public school is inserted, in order to identify strategies for articulation and care for students with disabilities. It is a qualitative study, characterized as a descriptive research. The data collection procedure was done through participant observation in the school environment and in places close to the school and semi-structured interview with the pedagogical coordinator of the school and the manager of the Family Health Strategy (ESF). The school has 1290 students, of whom 53 have a disability. The articulation between the school and the FHT occurs through the Health in the School Program (PSE) and through the referral of the students to attend the health service. As for students with disabilities, the ESF monitors some specific cases, however, the ESF and not even the municipality have a structure to meet all the specifics. Finally, we find that the school has a great demand for students with disabilities and despite the offer of specialized care, it needs complementary support.

Keywords: Education. Health services. Disabled persons.

Recebido em: 8/4/2019

Aceito em: 2/6/2019

\footnotetext{
${ }^{1}$ Licenciada em Educação Física pela Universidade Federal do Pampa. Especialista em Saúde Mental Coletiva pela Universidade Federal do Pampa. Mestranda do Programa de Pós-Graduação em Educação em Ciências: Química da Vida e Saúde da Universidade Federal do Pampa, Brasil. https://orcid.org/0000-0001-7232-2357.tati_mcs@hotmail.com

${ }^{2}$ Graduanda do curso de Fisioterapia, bolsista do Programa de Educação Tutorial - Práticas Integradas em Saúde Coletiva da Universidade Federal do Pampa.https://orcid.org/0000-0001-6106-0646. karol_abz@hotmail.com

${ }^{3}$ Doutorado em Ciências Biológicas (Bioquímica Toxicológica) pela Universidade Federal de Santa Maria, Brasil. Professor da Universidade Federal do Pampa. https://orcid.org/0000-0001-5254-6732.rodrigo.balk@gmail.com
} 
A década de 90 do século 20 caracteriza-se como um marco de mudanças na política educacional brasileira na perspectiva da inclusão.

Decretos, resoluções, recomendações e diretrizes foram promulgados de forma a orientar os sistemas educacionais em uma perspectiva inclusiva, tendo como princípio a igualdade, a equidade e o atendimento à diversidade em ambientes regulares de ensino (POKER; VALENTIM; GARLA, 2018, p. 128).

A Constituição Federal (1988), a Lei de Diretrizes e Bases da Educação Nacional (Lei no 9.394/96), o Estatuto da Criança e do Adolescente (BRASIL, 1990), o Plano Nacional de Educação na perspectiva da Educação Inclusiva (BRASIL, 2008), o Plano Nacional dos Direitos da Pessoa com Deficiência (BRASIL, 2011) e a Lei Brasileira de Inclusão da Pessoa com Deficiência (Lei no 13.146) (BRASIL, 2015), garantem o direito à educação pública e de qualidade às pessoas com deficiência. Estes instrumentos legais visam, sobretudo, a "assegurar às pessoas com deficiência a sua efetiva participação na sociedade, através da sua plena inclusão, com independência e autonomia" (REGIS; KABENGELE, 2018, p. 4).

Para tanto, a Lei № 9.394, de 1996, estabelece, no seu artigo 59, que os sistemas de ensino devem assegurar as/aos alunas/os com deficiências "currículos, métodos, técnicas, recursos educativos e organização específicos, para atender as suas necessidades", bem como, "professores do ensino regular capacitados para a integração desses educandos nas classes comuns" (BRASIL, 1996). A Política Nacional de Educação Especial na Perspectiva da Educação Inclusiva defende que a educação para pessoas com deficiência "[...] constitui um paradigma educacional fundamentado na concepção de direitos humanos, que conjuga igualdade e diferença como valores indissociáveis [...]" (BRASIL, 2008, p. 5).

Assim, a escola assegura que "o aluno com deficiência tenha acesso a um currículo flexível, a materiais adaptados, tecnologia assistiva, a avaliações diferenciadas", entre outras atribuições (ANTUNES; RECH; ÁVILA, 2016, p. 180), recaindo sobre a escola uma responsabilidade que, por vezes, ela não consegue assumir sozinha. Neste sentido, Hack e Carvalho (2018, p. 235) partem do pressuposto de que a efetividade da inclusão escolar requer contínua articulação em rede, com destaque para a intersetorialidade entre as políticas sociais de educação, saúde e assistência social, fazendo-se necessário, assim, a articulação com outras instituições, órgãos e associações, favorecendo o acompanhamento e atendimento integral da/o aluna/o.

As redes de apoio são exemplos de ações articuladas com profissionais dentro ou fora da escola, num espaço de debate compartilhando ideias, conhecimentos e alternativas construídas no grupo (PELOSI; NUNES, 2011). Diante de tais possibilidades, o estudo busca analisar o contexto, no qual se insere uma escola pública a fim de identificar as estratégias de articulação e atendimento as/aos alunas/os com deficiência.

\section{PERCURSO METODOLÓGICO}

Este estudo situa-se nos domínios da abordagem qualitativa, e é caracterizada, quanto aos objetivos, como uma pesquisa descritiva. A escola na qual o estudo foi desenvolvido, compõe a rede municipal de ensino de um município da Fronteira Oeste do Rio 


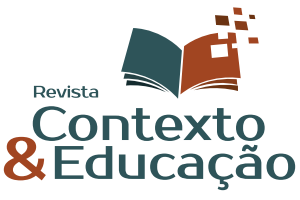

Educação Inclusiva e Redes de Apoio: reflexões a partir de uma realidade escolar

Grande do Sul, e foi escolhida por meio do método não probabilístico intencional. A delimitação da base de estudo justifica-se pela exequibilidade da pesquisa, pois procura conhecer uma situação complexa, suas variáveis e as inter-relações existentes, demandando uma imersão no contexto analisado e exigindo abertura dos espaços formativos da escola.

A referida escola está localizada na zona urbana, em um território formado por um complexo de bairros, abrangendo 11 localidades, estando situado na Região Sudeste do município, com aproximadamente 11.710 habitantes, conforme delimitado na Figura 1. A escola foi instituída a partir da necessidade das/os moradoras/es locais destes bairros em ter um lugar para que suas/es filhas/os pudessem acessar a educação sem o deslocamento excessivo, tendo em vista que estes bairros se localizam em região periférica.

Figura 1 - Mapa do município, delimitando o referido território

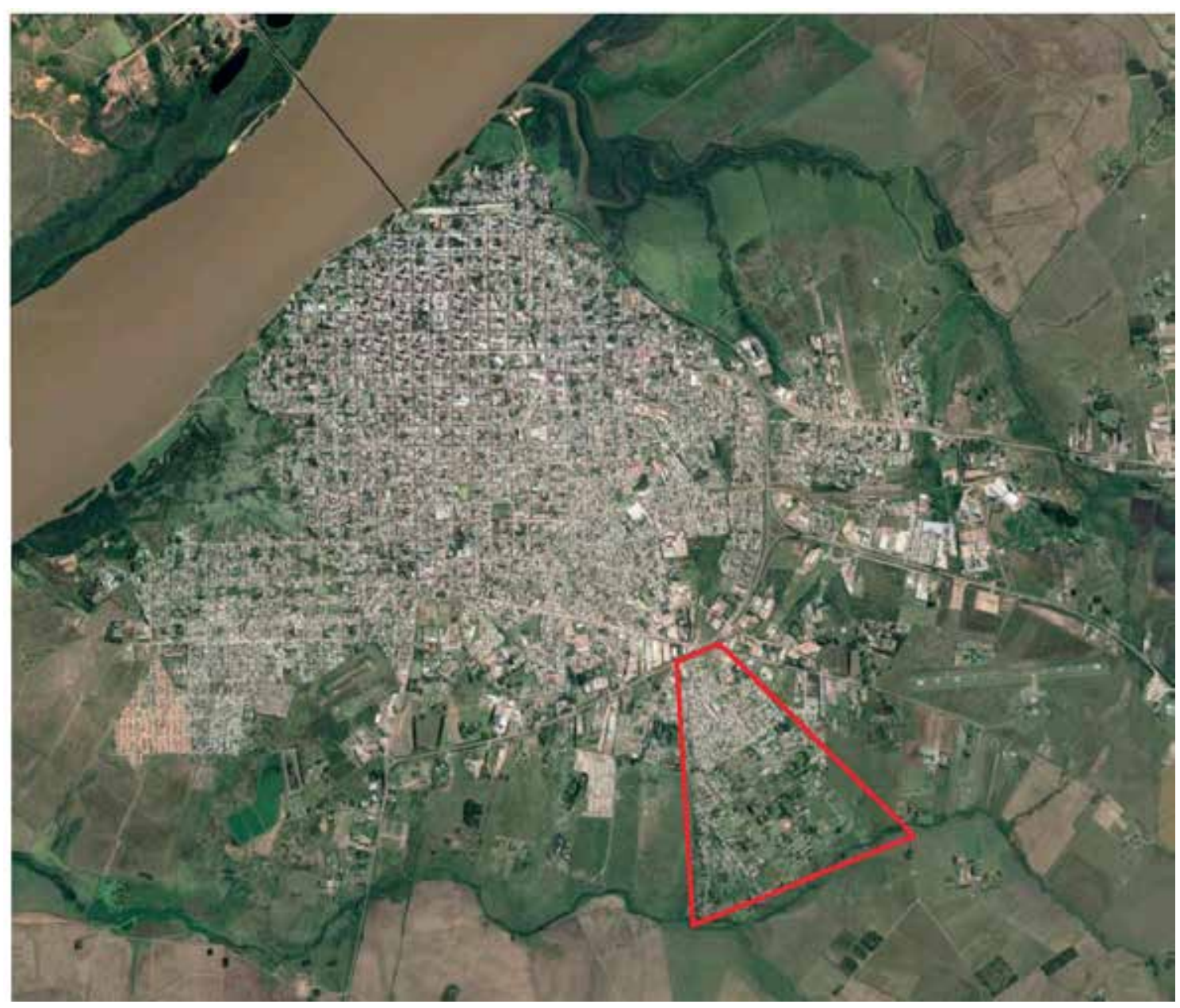

Fonte: Google Maps.

Além da escola onde o estudo foi desenvolvido, o complexo de bairros conta com mais uma escola de Ensino Fundamental, duas de Educação Infantil e uma escola de Ensino Médio. No que se refere aos serviços de saúde, o território possui duas Estratégias de Saúde da Família (ESF).

Para a coleta dos dados, a pesquisa foi desenvolvida em duas etapas, sendo a primeira a realização de um diagnóstico do ambiente escolar e da região onde a escola está localizada, com a finalidade de caracterizar o contexto em que as/os alunas/os estão in- 
seridas/os. A segunda etapa buscou identificar a articulação entre escola e serviços de apoio, sendo a ESF apontada como um dos serviços com que a escola se articula para o apoio e assistência as/aos alunas/os com deficiência. Os resultados foram organizados e serão apresentados em uma análise descritiva.

a) Diagnóstico observacional do contexto: foi utilizada a observação participante com registros no diário de campo. As observações foram realizadas no ambiente escolar, bem como nos ambientes próximos à escola, como a ESF e a comunidade onde a escola está localizada. Esta etapa foi feita durante os meses de agosto, setembro e outubro de 2018, três vezes por semana, em turnos variados. As observações seguiram um roteiro preestabelecido. Após cada observação foi realizado o registro no diário de campo, norteando ideias, reflexões e diálogos com as/os observadas/os.

Para complementar as observações foi feita a leitura e a análise do Projeto Político Pedagógico (PPP) da escola, visando a identificar de que forma a Educação Inclusiva é abordada no PPP e como está sendo tratada neste espaço.

b) Identificação da articulação entre escola e serviços de apoio: foi realizada entrevista semiestruturada com a coordenação pedagógica da escola e com a gestora da ESF adstrita, buscando identificar a articulação da escola com a ESF no atendimento às/os alunas/os com deficiência, no intuito de melhor compreender o contexto estudado. As entrevistas ocorreram após o período inicial de observação.

As entrevistas seguiram um roteiro preestabelecido, que foi construído especificamente para o presente estudo, constando questões referentes à comunicação e à articulação entre a escola e a ESF. As entrevistas foram feitas posteriormente às observações. Para a realização das entrevistas foi utilizado um gravador, no intuito de não perder nenhum detalhe expresso pelas/os profissionais. Após a coleta dos dados, as entrevistas foram transcritas.

As/os participantes assinaram o Termo de Consentimento Livre e Esclarecido antes de responder à entrevista. O estudo foi aprovado pelo Comitê de Ética em Pesquisa da instituição, sob o número de parecer 2.917.413, e seguiu as orientações da Resolução no 510/16 do Conselho Nacional de Saúde.

\section{RESULTADOS}

Os resultados alcançados com a coleta de dados foram organizados e descritos em dois momentos: "contexto escolar e a inclusão de alunas/os com deficiência" e "articulação entre escola e serviços de apoio".

\section{Contexto Escolar e a Inclusão de alunas/os com deficiência}

O município conta com uma população estimada de 129.580 habitantes (IBGE, 2014), sendo 93,6\% residente na área urbana. Atinge o IDHM de 0,7442, com uma estimativa de $12,2 \%$ de analfabetos. A rede municipal de ensino possui atualmente 7.411 matrículas no Ensino Fundamental, distribuídas em 16 escolas, sendo 10 localizadas na zona urbana e 6 na área rural.

Em relação à inclusão de alunas/os com deficiência no Ensino Fundamental, atualmente estão matriculadas/os 344 alunas/os com deficiência, conforme apresentado no Quadro 1. 
Quadro 1 - Instituições municipais e matrículas no ano de 2018

\begin{tabular}{lccc}
\hline Instituições & Quantidade & Total de alunas/os & $\begin{array}{c}\text { Alunas/os com } \\
\text { deficiência }\end{array}$ \\
\hline Educação Infantil & 15 & 4.806 & 99 \\
\hline Ensino Fundamental & 16 & 7.411 & 344 \\
\hline Total & 31 & 12.217 & 443 \\
\hline \multicolumn{4}{c}{ Fonte: Elaborado pelos autores (2019). }
\end{tabular}

Na referida escola atualmente estão matriculados 1.290 estudantes, distribuídos em três turnos. Destes 650 estudam no turno da manhã, 565 tarde e 75 noite. Por ser uma escola de Ensino Fundamental, são ofertadas vagas em turmas do $1^{\circ}$ ao $9^{\circ}$ anos. $O$ número de alunas/os com deficiência é de 53. Destas/es, 15 possuem laudo médico, de acordo com os dados disponibilizados pela Semed e especificados no Quadro 2. A escola possui o maior número de alunas/os com deficiência matriculadas/os na rede municipal de ensino.

A escola tem espaço físico de $4.378,52 \mathrm{~m}^{2}$ e 27 salas de aula, além de espaços de convivência e salas específicas, como sala de recursos, de apoio pedagógico, de multimídia, entre outros. A estrutura da escola apresenta características de acessibilidade física, no entanto alguns espaços e objetos ainda necessitavam de melhor projeção para atender às diferentes características e necessidades de todas/os as/os alunas/os.

Quadro 2 - Alunas/os com deficiência matriculadas/os na referida escola e na rede municipal de ensino

\begin{tabular}{lcc}
\hline Deficiência & Escola & Município \\
\hline Deficiência Intelectual & & 8 \\
\hline Síndrome de Down & 1 & 47 \\
\hline Intelectual & & 2 \\
\hline Deficiência Visual & 1 & 8 \\
\hline Cego & 2 & \\
\hline Baixa Visão & & 2 \\
\hline Deficiência Auditiva & 1 & 11 \\
\hline Surdez & 2 & 9 \\
\hline Baixa Audição & & 1 \\
\hline Deficiência Física & 1 & 5 \\
\hline Paralisia Cerebral & - & 19 \\
\hline Motricidade & - & 37 \\
\hline Membros Inferiores & & 17 \\
\hline Transtornos & 1 & 1 \\
\hline TEA & 2 & 177 \\
\hline Outros & - & 186 \\
\hline TDHA & - & 158 \\
\hline Altas Habilidades & 29 & 344 \\
\hline Dificuldades acentuadas de aprendizagem & 38 &
\end{tabular}

Fonte: Elaborado pelos autores (2019). 
Para o Atendimento Educacional Especializado ( $A E E$ ) a escola conta com 3 educadoras/es especiais atuando na sala de $A E E$, atendendo um total de 47 alunas/os, distribuídos nos turnos da manhã (18), tarde (23) e noite (6), segundo os dados atualizados pela coordenação pedagógica. Destas/es, 29 estão matriculadas/os nos anos iniciais e 18 nos anos finais, considerando que 11 são do sexo feminino.

$O$ atendimento na sala de AEE ocorre no contraturno escolar para as/os alunas/os do diurno, e para as/os alunas/os do noturno ocorre concomitante com a aula, porém em salas separadas. A escola conta com três auxiliares pedagógicos para acompanhamento das/os alunas/os em sala de aula.

O PPP da escola assegura sua filosofia para a prática educativa visando o senso de justiça, de verdade e de solidariedade do ser humano no exercício da cidadania. Destaca-se, ainda, que a escola objetiva proporcionar à comunidade escolar reflexões quanto à prática cidadã, mediante vivência de valores humanos, oportunizando a/ao educanda/o ser responsável, crítico, participativo e capaz de interagir em seu contexto social. Sua metodologia e a concepção epistemológica são sociointeracionistas, partindo prioritariamente de projetos contextualizados. A concepção epistemológica em que a escola se baseia fundamenta-se na construção do indivíduo na relação sociocultural e histórico-social.

Quanto ao processo avaliativo, a escola menciona em seu PPP um método especializado e adaptado para a avaliação de alunas/os especiais conforme suas dificuldades. Nos anos finais a coordenação pedagógica reúne-se para discussão das habilidades e competências de forma particular, seguindo a legislação. Já para os anos iniciais a/o responsável pela sala de recursos elabora um relatório para a/o professora/or titular da turma, que contribui com a avaliação.

\section{Articulação entre escola e serviços de apoio}

Inicialmente buscou-se identificar os serviços com os quais a escola se articula para dar apoio e assistência as/aos alunas/os com deficiência, sendo a ESF indicada como um dos principais serviços, em virtude da aproximação territorial. A articulação entre a escola e a ESF na realidade estudada ocorre por meio da comunicação direta com a coordenação da escola, que entra em contato com a ESF ou vice-versa, podendo a escola encaminhar as/os alunas/os baseada na demanda espontânea atendida pelo serviço de saúde ou por agendamento de consultas.

Nos casos das/os alunas/os com deficiência a gestora da ESF explica que [...] ocorre encaminhamento para psicóloga, ela atende através do NASF (Núcleo de Apoio a Saúde da Família) e encaminhamento para avaliação de crianças com alteração psicomotora ou de desenvolvimento (GESTORA ESF). Quando questionada sobre a aproximação do serviço de saúde com a escola, a gestora da ESF afirma que acontece por meio do Programa Saúde na Escola (PSE).

As atividades realizadas pelo PSE abordam diferentes temas preestabelecidos pelo Ministério da Saúde, ou conforme demanda da escola. De acordo, com a gestora da ESF, 
[...] as atividades geralmente são em forma de roda de conversa; as temáticas são gravidez na adolescência, DST/AIDS, saúde mental, segurança alimentar nutricional, métodos contraceptivos, práticas corporais e saúde bucal com periodicidade de $15 \mathrm{em} 15$ dias [...] (GESTORA ESF).

Em contrapartida, a escola, por intermédio da coordenadora pedagógica, afirma que as atividades do PSE, em sua maioria, são pontuais e caracterizam-se como uma tentativa de articulação entre as instituições, conforme extrato da seguinte fala,

[...] se tem uma tentativa um pouco maior, de que a escola e o posto façam um trabalho de parceria, então a enfermeira e as agentes de saúde vêm até a escola e desenvolvem algumas ações em dias específicos, com determinadas turmas [...] (COORDENADORA PEDAGÓGICA).

Em relação ao atendimento de alunas/os com deficiência nos serviços de saúde, no entanto, a coordenadora pedagógica explica,

[...] em relação aos alunos com deficiência, é bem complicado, porque eles precisam de um atendimento especializado que o município não possui né [...] na maioria das vezes, então, atendimento para as deficiências específicas a gente não tem (COORDENADORA PEDAGÓGICA).

Quanto aos outros serviços aos quais a escola se articula, a coordenadora pedagógica ressalta a inter-relação com profissionais residentes em saúde coletiva vinculados a uma instituição de Ensino Superior que, ao atuarem na ESF, oferecem apoio à escola: [...] gente acaba pedindo algum tipo de auxílio, algum atendimento diferenciado (COORDENADORA PEDAGÓGICA); auxílio este que contempla algumas especificidades por se tratar de atendimento especializado.

$O$ atendimento especializado ofertado por fisioterapeuta e profissional de Educação Física ocorre em uma sala com material específico para o atendimento especializado. A sala foi montada com recursos destinados para um projeto de extensão, também vinculado à instituição de Ensino Superior.

Cabe destacar, todavia, que a realidade observada na referida escola difere das demais escolas públicas do município. $O$ atendimento, ao ser ofertado na escola, facilita sua continuidade, tendo em vista a diminuição de empecilhos, como a distância e o acesso aos serviços de saúde.

\section{DISCUSSÃO}

Com a introdução de políticas de inclusão escolar, a partir da década de 90 do século 20 passou-se a vislumbrar outras possibilidades para o processo de escolarização das/os alunas/os com deficiência. Estas políticas traçam diferentes formas de apoio às pessoas com deficiência, a fim de favorecer o acompanhamento e a efetivação da inclusão escolar, a elaboração de legislações específicas, as questões pedagógicas da rotina escolar (documentos, metodologias, procedimentos avaliativos), a acessibilidade, o uso de tecnologias e outras (FROHLICH, 2018). 
Gomes (2014) ressalta que, para atender às necessidades específicas e individuais das/os alunas/os com deficiência, faz-se necessário adaptações no âmbito do sistema de ensino para a garantia de acesso e permanência na escola por meio de apoios como sala de recursos, auxiliares, cuidadores e acessibilidade. Diante de tais adaptações, é possível pontuar, durante a caracterização da escola na qual o estudo se desenvolve, a forma de elaboração do PPP, a organização do AEE para as/os alunas/os com deficiência e a estrutura física da escola; adequações que favorecem a inclusão e a permanência das/os alunas/os em virtude das características do território onde a escola se localiza.

É valorizada aqui, assim, a principal ideia da educação inclusiva, ao demonstrar que a/o aluna/o não deve se adequar à escola, mas ela a/ao aluna/o. Nesse sentido, menciona Gomes (2014),

incluir, é muito mais que oferecer ao "diferente" acesso ao ensino regular; implica necessariamente criar uma outra lógica para a escola pensar a educação para cada um e para todos os alunos, de forma que nenhuma criança deva estar fora dela (p. 89).

Apesar de a legislação brasileira ser propiciadora da inclusão, ela não garante, por si só, o acolhimento em ambiente escolar, sendo necessárias ações efetivas que contribuam para a superação dos preconceitos e a transformação das barreiras socioculturais tradicionalmente estabelecidas e que excluem a/o aluno com deficiência (REDIG; GLAT, 2017). Uma escola inclusiva, para Zerbato e Mendes (2018, p. 154), "requer a participação de toda a equipe escolar na construção de uma identidade e cultura colaborativa para o desenvolvimento de práticas mais abrangentes para acesso e aprendizado de todos os estudantes".

Diante da diversidade e das especificidades às quais a escola se depara ante as deficiências apresentadas no Quadro 2, incide sobre a figura da/o professora/or a responsabilidade de planejamento e adaptações práticas capazes de atender às diversas demandas das/os alunas/os, tornando a prática pedagógica um desafio diário. Zerbato e Mendes (2018) asseguram que a inclusão escolar não se faz somente dentro da sala de aula, sendo necessário que a/o professora/or busque a construção de práticas pedagógicas por meio de parcerias e colaboração com outras/os profissionais.

Quanto à articulação entre a escola e os serviços de apoio presentes no contexto estudado, salientamos a ESF pelas possibilidades de articulação por meio do atendimento especializado às/aos alunas/os, bem como ações de prevenção e promoção à saúde. O PSE, por sua vez, caracteriza-se, neste contexto, como um facilitador para o primeiro contato entre as instituições.

O PSE tem a finalidade de contribuir para a formação integral das/os alunas/os da rede pública de educação básica por intermédio de ações de prevenção, promoção e atenção à saúde. Segundo Batista, Mondini e Jaime (2017), o PSE é essencial para o enfrentamento da vulnerabilidade que pode acometer crianças e adolescentes em idade escolar, com o fortalecimento e a criação de vínculo entre saúde, educação e outras redes de serviços sociais.

Assim, o PSE caracteriza-se como um importante articulador das redes públicas de ensino e de saúde, porém, no referido contexto, por suas ações pontuais, pouco favorece esta articulação e a continuidade das ações propostas. 
Embora a legislação incite a necessidade de desenvolvimento e aplicação de estratégias de gestão intersetorial, os modelos de atendimento atualmente encontrados na área ainda reproduzem práticas setorializadas, encerradas em suas especializações e fragmentadas (HACK; CARVALHO, 2018, p. 239).

O processo de inclusão educacional consiste em um desafio que não está atrelado apenas à educação/escolar, pois demanda de projetos e ações interdisciplinares e intersetorializadas, tendo em vista que esse processo não se sustenta apenas nas ações do professor em sala de aula, mas em uma rede de cuidados e troca de saberes entre os profissionais que atuam em diferentes serviços (CÁRNIO et al., 2012). Evidencia-se, desta forma, a necessidade de se fortalecer as ações em conjunto entre escola e serviço de saúde no referido contexto.

Silva, Molero e Roman (2016) defendem as ações conjuntas entre os serviços da área da saúde e da educação, devendo os serviços de saúde transgredir as campanhas meramente informativas ou diagnósticas, de maneira a contribuir para uma atuação colaborativa e que supere a fragmentação dos saberes e fazeres nas diferentes instâncias do atendimento. A relação entre as áreas da saúde e da educação propicia o acompanhamento integral e de atenção as/aos alunas/os, favorecendo a/ao professora/or compreender as especificidades, os progressos de ensino-aprendizagem e as dificuldades de cada aluna/o, resultando em contribuições para o planejamento e desenvolvimento de sua prática pedagógica.

Conforme a Política Nacional de Educação Especial na perspectiva da Educação Inclusiva, existe a necessidade de uma oferta ampliada de serviços de apoio que ultrapassam o espaço escolar.

A educação especial direciona suas ações para o atendimento às especificidades desses estudantes no processo educacional e, no âmbito de uma atuação mais ampla na escola, orienta a organização de redes de apoio, a formação continuada, a identificação de recursos, serviços e o desenvolvimento de práticas colaborativas (BRASIL, 2008, p. 14).

Deste modo, Silva, Molero e Roman (2016) traçam algumas estratégias para a promoção de um sistema educacional efetivamente inclusivo, destacando,

a necessidade de reformulação da formação de profissionais de saúde - que precisam compreender os problemas e demandas escolares -, a articulação entre instituições acadêmicas e redes de serviços para o desenvolvimento de pesquisas, métodos e formação contínua, e a reestruturação do funcionamento escolar, a fim de que valorize professores e alunos e assim ofereça melhores condições de um fazer educativo que promova o desenvolvimento de todos (SILVA; MOLERO; ROMAN, 2016, p. 114).

Frohlich e Lopes (2018, p. 1002) apontam "uma grande ênfase nos serviços de apoio que se vinculam a diferentes profissionais externos à escola". As autoras destacam que, em sua grande maioria, os serviços e profissionais citados pertencem à área médica, psicológica e de assistência social, corroborando a realidade encontrada na referida escola. 
Pelosi e Nunes (2011) evidenciam que a parceria traçada entre a escola e os serviços de saúde tendem a beneficiar tanto as/os alunas/os quanto as/os professoras/es, que passam a contar com o apoio de outros profissionais. É necessário, no entanto, a continuidade e o retorno dos serviços de apoio à escola, tendo em vista as possibilidades de "flexibilizações e adaptações curriculares, avaliações diferenciadas e uso de diferentes metodologias" (FROHLICH; LOPES, 2018, p. 1.006). Busca-se, com isso, mudanças nas práticas escolares, direcionando ações aos interesses e necessidades individuais, considerando não apenas a deficiência, mas as potencialidades de cada sujeito.

\section{CONSIDERAÇÕES FINAIS}

De acordo com o breve diagnóstico do contexto escolar e do território onde a escola está inserida, averiguamos que a referida escola possui uma grande demanda de alunas/os com deficiência e, apesar da oferta de atendimento especializado, ainda resta um apoio complementar que a escola carece. O território no qual a escola está localizada apresenta alto índice de vulnerabilidade social. Desta forma, a escola e a ESF ocupam um espaço que vai além do ensino e do cuidado com a saúde, tornando-se essenciais para a comunidade em questão.

Quanto à articulação da escola e da ESF, percebemos que esta ocorre de forma pontual por meio do PSE e de atendimentos também pontuais no referido serviço de saúde, com pouco retorno para a escola, as/os alunas/os e familiares, evidenciando a fragmentação do atendimento e intensificando os desafios que se colocam para a efetividade do cuidado integral das/os alunas/os com deficiência.

Diante de tal contexto, compreendemos que a busca por integração entre a área da saúde e da educação em prol do desenvolvimento de um trabalho coletivo e contínuo com as/os alunas/os com deficiência, exige estratégias de ambas as áreas. Entre essas estratégias está a necessidade de garantir momentos de trocas e de planejamento, tendo o PSE o papel de promover o contato inicial e, a partir dele, fortalecer o vínculo entre as instituições. Também viabilizar ações que busquem a formação em serviço e o entendimento das/os profissionais da saúde quanto às demandas escolares, além do investimento na descentralização da escola, partilhando a responsabilidade quanto ao processo educacional inclusivo.

Por fim, reiteramos que a escola invista em estratégias de articulação e comunicação com a ESF, bem como com outros serviços que compõem a rede de apoio do município, a fim de complementar e dar continuidade ao cuidado das/os alunas/os com deficiência e assistência para suas famílias.

\section{REFERÊNCIAS}

ANTUNES, H. S.; RECH, A. J. D.; ÁVILA, C. C. Educação inclusiva e formação de professores: desafios e perspectivas a partir do Pacto Nacional pela Alfabetização na Idade Certa. Práxis Educativa, Ponta Grossa, v. 11, n. 1, p. 171-198, jan./abr. 2016.

BRASIL. Constituição da República Federativa do Brasil de 05 de outubro de 1988. 1988.

BRASIL. Lei no 9.394, de 20 de dezembro de 1996. Estabelece as diretrizes e bases da educação nacional (LDB). Diário Oficial da União, Brasília, DF, dez. 1996.

BRASIL. Lei no 8.069, de 13 de julho 1990. Dispõe sobre o Estatuto da criança e do adolescente e dá outras providências. Diário Oficial da União, Brasília, DF, jul. 1990. 
BRASIL. Lei no 13.146, de 6 de julho de 2015. Institui a Lei Brasileira de Inclusão da Pessoa com Deficiência - Estatuto da Pessoa com Deficiência. Brasília, DF, jul. 2015.

BRASIL. Lei no 13.005, de 25 de junho de 2014. Aprova o Plano Nacional de Educação - PNE e dá outras providências. Legislação Brasileira. Brasília, 2014.

BRASIL. Secretaria de Educação Especial. Política Nacional de Educação Especial na Perspectiva da Educação Inclusiva. Brasília: MEC; SEESP, 2008.

BRASIL. Decreto no 7.612, de 17 de novembro de 2011. Institui o Plano Nacional dos Direitos da Pessoa com Deficiência. Brasília, DF, nov. 2011.

BATISTA, M. S. A.; MONDINI, L.; JAIME, P. C. Ações do programa saúde na escola e da alimentação escolar na prevenção do excesso de peso infantil: experiência no município de Itapevi, São Paulo, Brasil, 2014. Epidemiol. Serv. Saúde, Brasília, 26(3), p. 569-578, jul./set. 2017.

CÁRNIO, M. S. et al. Escola em tempo de inclusão: ensino comum, educação especial e ação do Fonoaudiólogo. Revista Distúrbio de Comunicação, São Paulo, SP, v. 24, n. 2, p. 249-56, set. 2012.

FROHLICH, R. Práticas de apoio à inclusão escolar e a constituição de normalidades diferenciais. 2018. Tese (Doutorado em Educação) - Universidade do Vale do Rio dos Sinos - Unisinos, Programa de Pós-Graduação em Educação, São Leopoldo, 2018.

FROHLICH, R.; LOPES, M. C. Serviços de apoio à inclusão escolar e a constituição de normalidades diferenciais. Revista Educação Especial, Santa Maria. v. 31, n. 63, p. 995-1.008, out./dez. 2018.

GOMES, J. C. Implicações da inclusão escolar de alunos com deficiência intelectual e transtornos globais do desenvolvimento na prática docente. 2014, 233f. Dissertação (Mestrado) - Uninove, Programa de Pós-Graduação em Educação, São Paulo, 2014.

HACK, N. S.; CARVALHO, D. R. A relação das políticas de educação, saúde e assistência social frente aos desafios da educação inclusiva. Perspec. Dial.: Rev. Educ. e Soc., Naviraí, v. 5, n. 9, p. 234-252, jan./jun. 2018. IBGE. Instituto Brasileiro de Geografia e Estatística. Censo demográfico 2014. Disponível em: www.ibge. gov.br,http://www.cidades.ibge.gov.br/xtras/perfil.php?lang=\&codmun=432240\&searc=riogrande-do-sul| uruguaiana|infograficos:-informacoes-completas. Acesso em: 10 nov. 2018.

PELOSI, M. B.; NUNES, L. R. D. P. A ação conjunta dos profissionais da saúde e da educação na escola inclusiva. Rev. Ter. Ocup. Univ., São Paulo, v. 22, n. 1, p. 52-59, jan./abr. 2011.

POKER, R. B.; VALENTIM, F. O. D.; GARLA, I. A. Inclusão no Ensino Superior: a percepção de docentes de uma instituição pública do interior do Estado de São Paulo. Revista Psicologia Escolar e Educacional, São Paulo, n. especial, p. 127-134, 2018.

REDIG, A. G.; GLAT, R. Programa educacional especializado para capacitação e inclusão no trabalho de pessoas com deficiência intelectual. Ensaio: Aval. Pol. Públ. Educ., Rio de Janeiro, v. 25, n. 95, p. 330-355, abr. 2017.

REGIS, R. C. L. A.; KABENGELE, D. C. A pessoa com deficiência e o acesso à educação: uma política para equidade. Perspec. Dial.: Rev. Educ. e Soc., Naviraí, v. 5, n. 9, p. 3-18, jan./jun. 2018.

SILVA, C. C. B.; MOLERO, E. S. S.; ROMAN, M. D. A interface entre saúde e educação: percepções de educadores sobre educação inclusiva. Psicologia Escolar e Educacional, São Paulo, vol. 20, n. 1, p. 109-115, jan./abr. 2016.

ZERBATO, A. P.; MENDES, E. G. Desenho universal para a aprendizagem como estratégias de inclusão escolar. Educação Unisinos, v. 22(2), p. 147-155, abr./jun. 2018. 